Revista Eletrônica do Mestrado em Educação Ambiental

Programa de Pós-Graduação em Educação Ambiental

\title{
A Educação Ambiental Crítica e o pensamento freireano: tecendo possibilidades de enfrentamento e resistência frente ao retrocesso estabelecido no contexto brasileiro
}

\author{
Antonia Adriana Mota Arrais ${ }^{1}$ \\ Universidade de Brasília \\ https://orcid.org/0000-0002-2340-8258 \\ Marcelo Ximenes Aguiar Bizerril ${ }^{2}$ \\ Universidade de Brasília/Faculdade UnB Planaltina \\ https://orcid.org/0000-0002-2993-155X
}

\begin{abstract}
Resumo: o enfraquecimento das políticas ambientais e educacionais, na atualidade, afeta diretamente e silencia a Educação Ambiental (EA). Com isso, o presente ensaio é dedicado a promover uma discussão acerca da EA na contemporaneidade, principalmente no contexto brasileiro, apontando para a urgência do estabelecimento de uma EA que seja amparada nas premissas críticas, emancipatórias e transformadoras para a edificação de uma luta coletiva de resistência e enfrentamento a todas as adversidades que emergem nesses "novos" tempos. Assim, são apresentados alguns fundamentos e contribuições acerca da Educação Ambiental Crítica (EAC) e como o pensamento freireano, com seus elementos estruturantes - diálogo, a educação problematizadora e libertadora, o processo de conscientização, os temas geradores, a relação horizontal entre educando-educador, a ação-reflexão-ação e o desvelamento da realidade - que podem fornecer diretrizes para a construção de possibilidades de (re)pensar a EA diante da atual conjuntura.
\end{abstract}

Palavras-chave: Educação Ambiental. Educação Ambiental Crítica. Paulo Freire

\footnotetext{
1 Atualmente cursa doutorado em Educação em Ciências (PPGEduc/UnB). É mestre em Ensino de Ciências pela Universidade de Brasília (2016). Graduada em Ciências Naturais pela mesma instituição (2013). Atua na Secretaria de Estado de Educação do Distrito Federal (SEEDF). Possui experiência com a área de Ensino de Ciências, Ensino de Biologia e Educação Ambiental, com ênfase em linhas de pesquisa de educação científica e ensino-aprendizagem. e-mail: unbantonia@gmail.com

${ }^{2}$ Professor Associado da Universidade de Brasília, com doutorado em Ecologia pela Universidade de Brasília, e pósdoutorado em Políticas e Gestão do Ensino Superior pela Universidade de Aveiro (Portugal). Tem experiência nas áreas de: Educação Ambiental; Ensino de Ciências; Gestão do Ensino Superior; Comunicação Comunitária e Ecologia. e-mail: bizerril@unb.br
}

Rev. Eletrônica Mestr. Educ. Ambient. Rio Grande, v. 37, n. 1, p. 145-165, jan/abr. 2020.

E-ISSN 1517-1256 


\title{
Educación Ambiental Crítica y pensamiento freireano: tejiendo posibilidades de confrontación y resistencia ante el revés en el contexto brasileño
}

\begin{abstract}
Resumen: El debilitamiento actualmente de las políticas ambientales y educativas afecta directamente la Educación Ambiental (EA). El presente ensayo está dedicado a discutir la EA en la contemporaneidad, especialmente en el contexto brasileño, señalando la urgencia de establecer una EA con premisas críticas, emancipadoras y transformadoras, como base para una lucha colectiva de resistencia y enfrentamiento a toda las adversidades que surgen en los "nuevos tiempos". Así, se presentan algunos fundamentos y contribuciones de la Educación Ambiental Crítica (EAC) y del pensamiento de Paulo Freire, considerando sus elementos estructurantes - diálogo, la educación problematizadora y liberadora, el proceso de concientización, los temas generadores, la relación horizontal entre educador y aprendiz, el proceso de acción-reflexión-acción y la develación de la realidad - que pueden proporcionar pautas para la construcción de posibilidades para (re)pensar sobre EA frente a la coyuntura actual.
\end{abstract}

Palabras clave: Educación Ambiental. Educación Ambiental Crítica. Paulo Freire

\section{Critical Environmental Education and paulo freire's pedagogy: Weaving possibilities of confrontation and resistance in the face of setback in the brazilian context}

\begin{abstract}
: the weakening of environmental and educational policies nowadays directly affects Environmental Education (EE). The present essay is dedicated to discuss EE in contemporaneity, especially in the Brazilian context, recording for the urgency of establishing an EE with critical, emancipatory and transformative premises, as basis to a collective struggle of resistance and confrontation to the adversities emerged in the "new" times. Thus, some fundamentals and contributions on Critical Environmental Education (CEE) and Paulo Freire's Pedagogy are presented considering its structuring elements - dialogue, a problematizing and liberating education, the process of awareness, the generating themes, a horizontal relationship between educator and learners, the action-reflection-action process, and the reality analysis - can provide guidelines for the construction of possibilities for (re)thinking about $\mathrm{EE}$ in the current conjuncture.
\end{abstract} Keywords: Environmental Education. Critical Environmental Education. Paulo Freire

\section{Primeiras palavras: trajetórias do retrocesso no campo ambiental que contribuem para o silenciamento e enfraquecimento da EA}

Desde o governo de Dilma Rousseff até o de Michel Temer, em 2018, nota-se um processo de "perdas" e "derrotas" no campo ambiental brasileiro, afetando diretamente e enfraquecendo a Educação Ambiental (EA) no âmbito do Ministério da Educação e Cultura (MEC) e do Ministério do Meio Ambiente (MMA) (LAYRARGUES, 2018).

No entanto, a partir do ano de 2019, nota-se um aprofundamento desse retrocesso, uma vez que o governo, como prometido durante a campanha eleitoral, vem legitimando a “desproteção ambiental” e o ápice foi atingido ao propor a junção do MMA ao Ministério da Agricultura, órgão cuja orientação é fortemente influenciada pelo Agronegócio, proposta essa que foi rejeitada pelo próprio setor agrícola e, por isso, abandonada 
(TOZONI-REIS, 2019). A união entre os ministérios não ocorreu, no entanto, os representantes que ocupam os cargos desse setor, devido as suas ações e discursos, não aparentam ter base ideológica que preze pela preservação e proteção ambiental.

Logo no primeiro dia de 2019, a medida provisória $\mathrm{N}^{\circ} 870$ alterou significativamente as estruturas de muitos órgãos do governo que acarretaram na perda de importantes agendas ambientais relacionadas ao clima para os Ministérios da Agricultura e do Desenvolvimento Regional (BOURSCHEIT, 2019).

No MMA, setores importantes como a Secretaria de Biodiversidade e o Serviço Florestal Brasileiro, que agora faz parte do Ministério da Agricultura, tiveram como chefes um ex-lobista da Confederação Nacional da Indústria e um antigo ruralista que defende a liberação da caça aos animais silvestres (BOURSCHEIT, 2019). Enquanto isso, a pauta da bancada ruralista atua na busca pela liberação de novos agrotóxicos, na flexibilização das políticas e legislação de preservação à natureza e na redução das áreas de preservação permanente (APPs), dos territórios indígenas e quilombolas (DICKMANN; CECCHETTI, 2019; LOUREIRO, 2019).

Os discursos do próprio ministro do MMA apresentam cunho anti-ambientalista, apostando no desenvolvimento do turismo exacerbado em áreas protegidas, na exploração da biodiversidade amazônica, na privatização e também na concessão de áreas de reservas para o agronegócio, na mineração e atividade madeireira, sem controle e fiscalização (BOURSCHEIT, 2019).

Além do mais, o ministro não concordou com os dados sobre o desmatamento da Amazônia apresentados pelo Instituto Nacional de Pesquisas Espaciais (INPE), o que acarretou na exoneração do ex-diretor, Ricardo Magnus Osório Galvão, pelo presidente da República com a acusação de estar agindo a serviço de organizações não governamentais (ONG) que são contrárias ao desenvolvimento econômico. Registre-se que o INPE utiliza diversos sistemas de monitoramento para detectar o desmatamento na Amazônia, um deles, o Sistema de Detecção de Desmatamento em Tempo Real (DETER), emite um alerta sempre que há uma queimada superior a três hectares, com intuito de dar suporte a fiscalização e fortalecer a aplicação da lei para a redução do desmatamento e da degradação florestal, já o Projeto de Monitoramento de Satélites de Desmatamento da Amazônia (PRODES) calcula as taxas de desmatamento por meio de fotos de alta resolução de diferentes satélites (ESCOBAR, 2019).

Como consequência do ataque do governo ao INPE foram publicadas cartas de manifestação pública e moções em repúdio à demissão, na perspectiva de enfatizar a 
seriedade e validade do instituto em relação às pesquisas e monitoramentos realizados. A Sociedade Brasileira de Progresso da Ciência (SBPC), em um "Manifesto em Defesa do INPE", afirmou que "críticas sem fundamento a uma instituição científica, que atua há cerca de 60 anos e com amplo reconhecimento no país e no exterior, são ofensivas, inaceitáveis e lesivas ao conhecimento científico" (SBPC, 2019, p. 1). Algumas representações científicas importantes do país, elaboraram um manifesto afirmando que a “Amazônia e seu monitoramento ambiental são estratégicos para o Brasil. Não se trata apenas da manutenção da floresta como um sistema essencial para regular o processo de mudanças climáticas, de interesse internacional, mas também da preservação da riquíssima biodiversidade" (DAVIDOVICH et al. 2019, p. 2).

Esse acréscimo no desmatamento não pode ser descolado da postura e das medidas reais assumidas pelo atual presidente, que é um crítico ferrenho dos regulamentos ambientais e de sua aplicação, uma vez que acredita que tais mecanismos impedem o progresso econômico do Brasil. Em 2019, as multas e a fiscalização foram praticamente paralisadas, aumentando o grau de impunidade, de forma que os promotores do desmatamento foram apenas notificados de que infringiram os regulamentos, sem a aplicação de nenhuma medida coercitiva (FEARNSIDE, 2019).

Cabe ressaltar que a intensificação desse processo foi iniciada já no governo de Michel Temer mediante a aprovação da PEC 65/2012, que substitui os licenciamentos ambientais por estudos de impacto ambiental, permitindo assim uma maior flexibilização para ações de desmatamento, e também por meio da PEC 241/2016 que congelou os gastos e que afetou e continuará comprometendo o orçamento do MMA nos próximos anos, influenciando diretamente no funcionamento de institutos nacionais que controlam a Amazônia, como Instituto Brasileiro do Meio Ambiente e dos Recursos Naturais Renováveis (IBAMA) e o Instituto Chico Mendes de Conservação da Biodiversidade (ICMBio) (PEREIRA et al., 2019).

Outra situação que merece destaque diz respeito ao derramamento de óleo que acometeu diversas praias do Nordeste e algumas do Sudeste desde o final de agosto de 2019. Esse derramamento trouxe e trará diversos impactos ambientais e sociais, pois a pesca e o turismo, que são fontes de renda para muitas pessoas, foram inviabilizados. Ao invés de uma articulação precisa e urgente com os Estados para a inserção de um plano de contingência, o governo federal optou por uma postura acusatória buscando culpados para o derramamento, levantando até mesmo hipóteses de conspirações internacionais. Devido à falta e a demora da intervenção do governo federal, em algumas cidades a própria Rev. Eletrônica Mestr. Educ. Ambient. Rio Grande, v. 37, n. 1, p. 145-165, jan/abr. 2020. E-ISSN 1517-1256 
comunidade agiu para retirar as manchas de petróleo da água, gerando uma situação preocupante, uma vez que tais indivíduos, ao entrarem em contato com o material sem o devido cuidado, estariam colocando a sua própria saúde em risco (MARETTI, 2019).

Não se pode esquecer também da minimização da culpa pelo desastre causado pela mineradora Vale do Rio Doce, como no caso de Brumadinho em Minas Gerais (DICKMANN; CECCHETTI, 2019). Essa é apenas uma dentre as inúmeras ações que a Vale realizou em favor da exploração mineral sem os devidos cuidados ambientais e sociais, demonstrando insuficiente preocupação com as famílias atingidas (MAB, 2019).

Diante das situações expostas, nota-se que as promessas evidenciadas no plano de governo, ao serem postas em prática, têm resultado em descaso com o meio ambiente em prol dos interesses mercadológicos. O ataque ao meio ambiente também se dá indiretamente por diversas outras manifestações do governo tais como tentativas de criminalização dos movimentos sociais, de desmonte e desmoralização das universidades públicas e institutos federais, e consequentemente da ciência, afronta aos quilombolas, ribeirinhos, indígenas e LGBTQI+, ataques à classe dos professores e a figuras educadoras de destaque como Paulo Freire, desdenho com a historicidade dos direitos humanos e na busca de um realinhamento ideológico do país aos Estados Unidos da América, sobretudo ao governo de Donald Trump (DICKMANN; CECCHETTI, 2019; LEHER, 2019).

É possível dizer que um dos mais severos ataques à democracia foi a tentativa de exclusão da participação social nos processos políticos decisórios, por meio do decreto $\mathrm{N}^{\circ}$ 9.759, de 11 de abril de 2019, que extinguiu e estabeleceu diretrizes, regras e limitações para colegiados da administração pública federal, incluindo conselhos, comitês, comissões, grupos, juntas, equipes, mesas, fóruns e salas (BRASIL, 2019). Apesar do plenário do Superior Tribunal Federal ter limitado tal decreto, deliberando pela não extinção dos conselhos e outros colegiados cuja existência já estava prevista em lei, esse documento extinguiu instâncias compostas por representantes da sociedade civil que eram atuantes na gestão pública para a elaboração de políticas públicas importantes em diversas áreas (BRASIL, 2019; NOGUEIRA; MEDEIROS, 2019; SENNA, 2019).

A conjuntura evidenciada no campo ambiental brasileiro contribui diretamente para o silenciamento, retrocesso e enfraquecimento da EA, a começar pela Base Nacional Comum Curricular (BNCC), recentemente elaborada em meio a controvérsias e debates, e o Plano Nacional de Educação (PNE) 2014-2024. Esses são os principais documentos norteadores que embasam a educação escolar atualmente, que, no entanto, evidenciam um certo silenciamento da EA nos seus textos, e adotam, muito timidamente, um novo 
discurso direcionado em uma educação para o desenvolvimento sustentável e para a sustentabilidade (FRIZZO; CARVALHO, 2018). Nesse sentido, Loureiro (2012) defende que não há necessidade de uma educação para a sustentabilidade, meio ambiente ou desenvolvimento sustentável, mas uma educação que assegure a educação ambiental e a formação humana como princípio elementar.

Em uma outra perspectiva analítica, Behrend, Cousin e Galiazzi (2018, p. 81) apontam que existe a presença da EA no documento da BNCC, mas em um viés mais conservador e naturalista, como pode ser notado pelo uso de expressões como "consciência ambiental" e "conservação ambiental", no decorrer do texto, ao procurar unidades de significações referentes ao campo. Uma possível justificativa para a exclusão da perspectiva transformadora da EA é porque esta [...] "vai de encontro à política neoliberal em expansão no país, que aposta no sucateamento da Educação Básica, na alienação dos trabalhadores e na exploração do ser humano e dos recursos naturais".

Sem dúvida o tratamento da EA como política pública, e sua consequente estruturação no Estado por meio do Órgão Gestor da Política Nacional de Educação Ambiental, foi um dos grandes avanços do Brasil na área ambiental nesse início do século 21 (SORRENTINO et al., 2005). Todavia, na mesma medida, um dos principais ataques à EA foi justamente a extinção da Coordenação Geral de Educação Ambiental, estruturada na extinta Secretaria de Educação Continuada, Alfabetização, Diversidade e Inclusão/Mistério da Educação e Cultura (SECADI/MEC) e do Departamento de Educação Ambiental do MMA, inviabilizando o Órgão Gestor (GOUVEIA, 2019).

Atualmente, mais do que nunca, ao considerar esse contexto social e político vivenciado, se faz necessário o (re)pensar a EA na certeza de promover a sua fortificação, com o intuito de desenvolver olhares que considerem o ambiente em seus aspectos além do natural, ou seja, em suas faces históricas, culturais, sociais e políticas, principalmente em tempos obscuros como estes que aprofundam e legitimam a degradação ambiental (TOZONI-REIS, 2019).

Nesse sentido, o presente ensaio tem o objetivo de apontar para a urgência do estabelecimento e a efetivação de uma EA com a certeza do seu viés político, amparada nas premissas críticas, emancipatórias e transformadoras para a edificação de uma luta coletiva de resistência e enfrentamento a todo esse retrocesso que emerge nesses "novos" tempos. Com isso, os elementos estruturantes da pedagogia freireana, como o diálogo, a educação problematizadora e libertadora, o processo de conscientização, os temas geradores, a relação horizontal entre educando-educador, a ação-reflexão-ação e o 
desvelamento da realidade podem auxiliar na demarcação de um posicionamento teóricoprático e na construção de novas possibilidades para o fortalecimento e o (re)pensar acerca de qual EA pretendemos e queremos diante da perspectiva política e ambiental existente.

\section{(Re)afirmando posicionamentos: do emaranhado de EAs, por quê a Crítica?}

As distintas práticas e entendimentos em relação à crise socioambiental existente instituíram um conjunto de formas de fazer EA no espaço escolar, tornando-se um campo marcado pelo caráter contraditório, diversificado, conflitivo e complementar (LOUREIRO; LIMA, 2012). Dessa forma, existem aqueles projetos de EA que possuem uma base teórico-prática mais conservadora e outros que constituem-se de aspectos que são radicalmente vertidos para a emancipação e transformação da sociedade. EA crítica, ecopedagogia, EA feminista, alfabetização ecológica, EA holística e EA biorregionalista, são apenas alguns dos exemplos que caracterizam a pluralidade de intencionalidades educativas que permeiam o campo da EA (LAYRARGUES, 2004; SAUVÉ, 2005).

A Educação Ambiental Crítica (EAC), no âmbito brasileiro, emergiu como uma espécie de releitura da EA que era vista como comportamentalista, tecnicista ou com alternativas meramente biologizantes e instrumentalistas. Com isso, a EAC tornou-se um núcleo orientador desse campo e trouxe ao debate reflexões e considerações importantes da ecologia política, da complexidade e da ética socioambiental. Entretanto, cabe salientar que a EAC não pretende propor a uniformização do pensamento desse campo que é marcado por saberes e práticas tão plurais e diversificadas, nem tampouco se definir como um corpus com conhecimentos e ações superiores, no entanto ela aguça o questionamento, o diálogo, a busca pelo novo e o enfrentamento das situações de desigualdade social e injustiça socioambiental (LIMA, 2009; LAYRARGUES; LIMA, 2014).

A partir da década de 1990, educadores ambientais que apresentavam um olhar mais crítico propuseram a efetivação da EAC. Na década seguinte, a partir do ano de 2003, a EAC foi sendo gradualmente incorporada às normatizações e políticas de Estado, apesar de não ser totalmente consolidada (MACHADO; MORAES, 2019; LOUREIRO; 2006).

No entanto, Machado e Moraes (2019) advertem que mesmo com essa tentativa de oficialização da EAC nos governos progressistas (2003-2016), os casos de degradação e injustiça ambiental continuavam se ampliando. Em determinadas situações, a EA acabou atuando como instrumento de legitimação de injustiças com políticas "compensatórias", nas quais educadores ambientais eram pagos como consultores para "mitigar os impactos 
ambientais e impor uma maior aceitação ao inevitável processo de desenvolvimento sustentável", ou seja, acabavam seguindo caminhos vertidos pela própria lógica daquilo que questionavam, apresentando posturas incongruentes e contraditórias (MACHADO; MORAES, 2019, p. 49).

Loureiro (2006) destaca que mesmo em um governo que dialogava com os movimentos sociais, os interesses continuavam vertidos para os interesses mercadológicos. Nesse viés, Torres (2018, p. 162) salienta que "assumir um discurso progressista não caracteriza uma prática libertadora de caráter crítico-transformador voltada à humanização dos sujeitos, muito pelo contrário, se volta à ideologização (manipulação do real) das massas" $[\ldots]$.

Se em um governo que em tese era aberto a troca, ao diálogo e a escuta tais problemas continuavam emergindo, no contexto atual se faz urgente questionar as práticas ingênuas e acríticas, principalmente, frente ao "anti-ecologismo". Esse conceito ainda não é consolidado na área ambiental, contudo é caracterizado pela difusão de práticas que fomentam o silenciamento da denúncia da degradação ambiental e a priorização da extração dos recursos naturais em prol de interesses econômicos, dificultando a vigilância e a proteção ambiental e difamando quem acredita em um modelo de desenvolvimento alternativo ao existente atualmente (LAYRARGUES, 2018).

Diante dessa realidade, é importante que a EAC agregue à sua pauta educativa a luta pelo enfrentamento político da perda das institucionalidades ambientais, os conflitos e injustiças ambientais e o sucateamento dos órgãos ambientais, pensando em alternativas que evitem o seu retrocesso e considerando que as ações podem ir além da visão conservacionista e pragmática, ao investir em um diálogo mais crítico e anticapitalista, e que tenha um viés de transformação alinhado com a construção de sociedades sustentáveis (LAYRARGUES, 2017).

Porém, para além do estabelecimento e a efetivação dessa EA, ao considerar a sua possibilidade como um instrumento de luta e resistência frente ao retrocesso ambiental, é crucial também que ocorra uma demarcação teórico-prática acerca dessa EA, para que não haja um esvaziamento e uma construção reducionista de discurso e da práxis nesse campo (SILVA, 2009).

A EAC está ancorada nos pressupostos da Teoria Crítica do Conhecimento, ou seja, é diretamente vinculada às reflexões estabelecidas pelos representantes da Escola de Frankfurt que utilizaram do método dialético elaborado por Karl Marx e que também influenciaram a construção da pedagogia libertadora de Paulo Freire (LOUREIRO, 2006). 
Loureiro (2005, p. 35) explicita que a EA que se fundamenta na Teoria Crítica não pode ser vista como genérica e servir de nomeação para qualquer atividade/ação de EA, em um âmbito instrumentalista ou reprodutivista, mas deve fundamentar as práticas que buscam estabelecer uma [...] "práxis social e processo de reflexão sobre a vida e a natureza, contribuindo com a transformação do modo como nos inserimos e existimos no mundo".

Como produto dessa articulação entre EA e Teoria Crítica do Conhecimento, na literatura é possível encontrar concepções acerca da EAC com diferentes objetivos, posicionamentos e finalidades pedagógicas, epistemológicas e filosóficas (TREIN, 2012; TORRES, 2018). Carvalho (2012) considera que um posicionamento que define esse viés de EA é a visão da educação como um processo de humanização que tem como pressuposto a formação de um sujeito humano, enquanto ser histórico e social, focado na responsabilidade com os outros e pelo mundo em que ele vive e atua.

Complementarmente, Silva e Pernambuco (2014, p. 123) destacam que [...] "só é possível pensar em uma EA crítica quando esta for balizada pelo seu contexto sociocultural e econômico, quando assumir a abordagem interdisciplinar como uma exigência epistemológica para a apreensão da problemática ambiental". Lima (2009) afirma que um elemento de destaque na EAC é a crítica à razão moderna, rejeitando o antropocentrismo, a existência de uma neutralidade ideológica e o tecnicismo como fonte de resolução das questões ambientais e a instrumentalização para a dominação dos seres humanos e da natureza.

Para Torres, Ferrari e Maestrelli (2014, p. 14), “a EA crítica pode ser compreendida como uma filosofia da educação que busca reorientar as premissas do pensar e do agir humano na perspectiva de transformações das situações concretas e limitantes de melhores condições de vida dos sujeitos - o que implica mudança cultural e social". Além do mais, a EA [...] "necessita vincular os processos ecológicos aos sociais na leitura de mundo, na forma de intervir na realidade e de existir na natureza" (LOUREIRO, 2007, p. 66).

Guimarães (2004) afirma que a EA como "crítica" se faz necessária para contribuir para a transformação de uma realidade que é pautada em uma profunda crise socioambiental e que, entretanto, está vertida em um movimento de constituição dessa conforme os interesses dominantes a favor do capital, simplificando-a e fragmentando-a, sem considerar a sua totalidade e complexidade. Um dos exemplos recentes mais emblemáticos dessa situação foi proporcionado no contexto da pandemia causada pelo Covid-19. Diante da imposição do isolamento social como forma de combate ao vírus, o mundo assistiu à defesa enfática que mandatários mundo afora, com destaque para o Rev. Eletrônica Mestr. Educ. Ambient. Rio Grande, v. 37, n. 1, p. 145-165, jan/abr. 2020. E-ISSN 1517-1256 
presidente brasileiro, fizeram do sistema econômico em detrimento da saúde e da vida humana.

Ao considerar elementos que caracterizam a EAC, como a crítica à sociedade capitalista e a razão moderna, a superação da dicotomia sujeito-objeto, teoria-prática e natureza-sociedade, a urgência por uma educação humanizadora que leve em conta o contexto cultural dos indivíduos para a transformação das situações concretas e o seu sentido político (GUIMARÃES; 2004; LOUREIRO, 2005, 2006; LIMA, 2009; CARVALHO， 2012; SILVA; PERNAMBUCO， 2014， TORRES; FERRARI; MAESTRELI, 2014), entende-se que esta pode favorecer a instrumentalização de atores sociais que possam, além de desvelar a realidade, agir de modo coletivo e em um exercício de cidadania para a transformação e intervenção no mundo, principalmente no contexto atual marcado por tantas injustiças, contradições, desigualdades e pelo descaso político com o meio ambiente. Ou seja, a EAC objetiva a construção de espaços educativos que possam superar as ideias hegemônicas por meio de práticas que visam a mobilização de novas condutas para além da mera transmissão de conhecimentos ecológicos, e apostam no protagonismo e na cidadania ativa, na articulação entre os diferentes saberes e no exercício de um movimento coletivo para a transformação da sociedade atual, por isso ela se destaca em relação a outras propostas de EA (GUIMARÃES, 2004), e se faz necessária diante do retrocesso ambiental.

É diante desse contexto que o pensamento freireano, com seus elementos estruturantes, contribui para a implementação e demarcação de uma vertente problematizadora cujo objetivo central é a ruptura do senso comum de uma EA conservadora, conteudista, comportamental, instrumental, acrítica, a-histórica e neutra, além de fomentar o [...] "enfrentamento e superação das formas de opressão, controle e poder autoritário" [...] (LAYRARGUES, 2014, p. 12).

\section{O pensamento freireano como base teórico-metodológica para a EAC}

A pedagogia crítica de Paulo Freire retrata a responsabilidade com uma prática educativa libertadora dos seres humanos e do mundo, por meio da ação e reflexão, contra o cenário de opressão e injustiça, almejando a construção de uma nova sociedade que, sempre em transição, possa se fazer mais justa e democrática, em favor de uma ética universal do ser humano. Ele constrói um pensamento que considera a totalidade do ser humano, sua historicidade e a sua condição de ser inacabado e inconcluso, que em sua ação 
transformadora e reflexiva, pode fomentar um novo projeto societário (PERNAMBUCO; SILVA, 2006; FREIRE, 2016).

Com isso, os pensamentos teóricos e práticos de Freire possuem importantes implicações para a EA ao: (i) explorar abordagens além da concepção "bancária"; (ii) discutir o processo de transição da consciência ingênua para a crítica por meio de uma educação libertadora, problematizadora e popular, voltada para a superação da opressão e dos efeitos do capitalismo na desagregação entre humanidade e natureza; (iii) apostar na educação como um processo dialógico pelo qual os seres humanos se educam, em conjunto, mediatizados pelo mundo, e que não pode ser resumida a puro ativismo; (iv) desvelar as situações-limites que marcam a realidade opressora e desumanizante; e (v) acreditar em uma educação que prioriza o desenvolvimento de um pensamento crítico para o rompimento de tais situações, evidenciando uma preocupação com a injustiça e exclusão social que atinge as classes populares (FREIRE, 2016; LOUREIRO, 2006; PERNAMBUCO; SILVA, 2006).

No livro "Pedagogia da Autonomia: saberes necessários à prática educativa", Freire expõe uma preocupação com o desvelamento e ação para a transformação da realidade socioambiental concreta e das situações de desigualdade e injustiça social que marcam a sociedade capitalista, propondo a seguinte reflexão:

Por que não aproveitar a experiência que têm os alunos de viver em áreas da cidade descuidadas pelo poder público para discutir, por exemplo, a poluição dos riachos e dos córregos e os baixos níveis de bem-estar das populações, os lixões e os riscos que oferecem à saúde das gentes. Por que não há lixões no coração dos bairros ricos e mesmo puramente remediados dos centros urbanos? (FREIRE, 1996, p. 30).

Segundo Dickmann e Carneiro (2012), em referência às contribuições expressas no livro citado anteriormente (FREIRE, 1996), a perspectiva freireana aponta para o reconhecimento dos sujeitos como seres que podem, além de refletir, ler, criticar e analisar a realidade, atuar na transformação do mundo para a superação das posturas simplistas da realidade-ambiente em prol do estabelecimento de atitudes coerentes e responsáveis pela prevenção e superação de problemas socioambientais.

Nesse sentido, Freire postula que a educação não pode ter uma fórmula prescritiva, nem assumir uma forma de impor uma consciência à outra, uma vez que esse tratamento produz uma situação opressora, com ações desumanizadoras que retiram a autonomia para a resolução de suas próprias demandas. Assim, a educação como prática de liberdade 
(FREIRE, 2013) se faz urgente em um contexto como o atual, no qual as pautas da elite são favorecidas em detrimento das necessidades das minorias, aumentando as desigualdades sociais, a exclusão e o descaso com o meio ambiente.

A libertação autêntica é a práxis que resulta na ação e reflexão dos seres humanos sobre o mundo com o intuito de transformá-lo (FREIRE, 2016). O ser mais, diferente do ter mais, é alcançado quando os seres humanos estão procurando constantemente e permanentemente o conhecimento de si e do mundo, ao romper com o processo de desumanização e atuar em comunhão para efetivar laços de solidariedade e de luta pela emancipação dos que estão submetidos à dominação (FREIRE, 2013).

Para Freire (2016, p. 40), "uma educação que pretendesse adaptar o homem estaria matando suas possibilidades de ação [...]. A educação deve estimular a opção e afirmar o homem como homem. Adaptar é acomodar, não transformar”. Assumir a EA sob a concepção "bancária" é narrar a realidade como algo estático e que é alheio a experiência dos indivíduos, valorizando apenas o aspecto comportamental para que os grupos sociais se adequem às posturas e valores que são estabelecidos como "ecologicamente corretos" pela classe dominante e aceitem a sociedade tal como ela é, sem problematizar e questionar a sua condição no mundo (FREIRE, 2013; LOUREIRO, 2006).

Um espaço que pode fortalecer essa resistência e construir e edificar as lutas, apesar de não ser a "tábua da salvação", é a escola. Mesmo estando inserida fortemente no contexto de reprodução da sociedade capitalista, a escola é um ambiente frutífero para a produção de relações mais justas que prezem pelo diálogo, democracia e por práticas mais igualitárias e humanizadoras, mediante à abordagens teórico-metodológicas que priorizam a perspectiva interdisciplinar, crítica e problematizadora; a contextualização; a articulação entre as dimensões local e global; a avaliação crítica; a ação participativa e o caráter contínuo e permanente da EA para a formação de sujeitos ativos no processo de transformações sócio-histórico-culturais (TORRES; FERRARI; MAESTRELLI, 2014; TORRES, 2018).

Assim, compreende-se que nas ações que envolvem a EAC é importante considerar as lentes e as visões que as pessoas têm em relação ao mundo, uma vez que dependem das interações e experiências que os indivíduos estabelecem com seus contextos culturais e sociais. E é por meio da educação que o sujeito consegue realizar novas leituras do mundo e de si mesmo (CARVALHO, 2012; FREIRE, 2016).

De fato, a EA torna-se limitante quando as intervenções são reduzidas a uma atuação autoritária e vertical na qual o educador apresenta, de forma acabada, problemas Rev. Eletrônica Mestr. Educ. Ambient. Rio Grande, v. 37, n. 1, p. 145-165, jan/abr. 2020. E-ISSN 1517-1256 
socioambientais. Tais situações pouco, ou em quase nada, contribuem para a construção do pensamento crítico, visto que a realidade é imposta como algo acabado e que não é passível de transformação.

Mediante à essa visão distorcida e superficial de educação, a mobilização de uma consciência crítica é minimizada e a passividade não possibilita ao sujeito agir pela transformação do mundo, estimulando a sua ingenuidade e não o pensar autêntico e crítico. Tal viés colabora para que a educação favoreça a reprodução da lógica capitalista e a prática da dominação (FREIRE, 2016). Portanto, é preciso romper com essa consciência ingênua que é marcada pelo [...] "simplismo na interpretação dos problemas, isto é, encara um desafio de maneira simplista ou com simplicidade. Não se aprofunda na casualidade do próprio fato. Suas conclusões são apressadas, superficiais" (FREIRE, 2016, p. 52).

A crise socioambiental não pode ser vista com o foco resolutivo na inserção de práticas ingênuas voltadas para boas intenções de respeito à natureza, posto que é um problema que exige a conexão entre várias áreas, envolve a disputa de territórios do conhecimento e do social, e é a forma de lidar, criticar, problematizar e atuar nessa situação que definirá nossa existência e permanência no mundo (CARVALHO, 2012).

No entanto, o processo de mudança de consciência ingênua para crítica não é algo linear, trivial e automático, tendo em vista que demanda uma prática educativa de conscientização que seja crítica, dialógica e democrática com o intuito de mobilizar a capacidade de agir e tomar decisões conscientes em relação ao mundo (FREIRE, 2016; FREITAS, 2018). Assim, a educação problematizadora, de cunho autenticamente reflexivo e de ação, torna-se um instrumento que possibilita a conscientização para a transição da consciência ingênua rumo à consciência crítica (TOZONI-REIS, 2006; FREIRE, 2016).

A consciência crítica é caracterizada pelo reconhecimento de uma realidade que não é estanque e fechada, mas que pode ser transformada e moldada, pelo anseio da análise profunda dos problemas envoltos e os princípios de sua causalidade, pela aposta no diálogo, no engajamento sociopolítico, na receptividade diante do novo, na investigação e na indagação, e é, por isso, adversa a uma postura quieta, apática e passiva (FREIRE, 2016). Ora, essa forma de pensar é exatamente a dominante no meio universitário e que tanto contradita com perfis autoritários e fundamentalistas, sendo por isso mesmo razão dos ataques do governo na tentativa de desmonte e desmoralização das universidades públicas, como bem analisa Leher (2019). A conscientização, como instrumento de conhecimento da realidade de vida e instituição da práxis, pode ser viabilizada pelo diálogo e criticidade, [...] "a construção de alternativas para melhores condições de vida no lugar 
onde vivem, desenvolvendo, assim, a experiência do potencial emancipatório das temáticas socioambientais tornando a educação um espaço para a construção da cidadania ambiental" (DICKMANN; CARNEIRO, 2012, p. 95; FREIRE, 2013). Sobretudo, a conscientização não é restringida ao caráter subjetivo e reconhecimento puro de tais temáticas, mas envolve a preparação dos seres humanos para a luta e ação contra as adversidades que dificultam a sua humanização (FREIRE, 2013).

Na perspectiva da EAC, a conscientização exige uma dinâmica de desvelamento da realidade, atuação participativa e dialógica frente à superação das relações de dominação e opressão entre ser humano e o ser humano-natureza, não devendo estar pautada apenas na condição de refletir e pensar acerca da condição de existência sem promover o agir (LOUREIRO, 2006).

Com isso, o diálogo é um instrumento fundamental para que os [...] "homens ganhem significação enquanto homens". É o encontro dos homens para o ser mais, não podendo se restringir ao ato de depositar ideias e argumentos de um ser no outro, nem meramente o simples compartilhamento de informações, uma vez este se estabelece nas relações de A com B e nunca de A sobre B ou de A para B (FREIRE, 2013, p. 109). O diálogo não se faz para nivelar ou reduzir um ao outro, nem é favor que um faz ao outro, não é tática para confundir o outro, mas [...] "implica, ao contrário, um respeito fundamental dos sujeitos nele engajados, que o autoritarismo rompe ou não permite que se constitua" (FREIRE, 1992, p. 118).

É na dialogicidade verdadeira que os sujeitos, que se reconhecem como inacabados e inconclusos, crescem e aprendem nas diferenças e no respeito a elas (FREIRE, 2017). Como fundamento primordial para uma educação libertadora e de pronúncia ao mundo, o diálogo verdadeiro existe apenas se houver humildade, não se restringindo a um ato arrogante e de seres seletos que se consideram dotados de capacidade intelectual superior. É um ato que é fundado na fé. "Fé no seu poder de fazer e de refazer. De criar e recriar. Fé na sua vocação de ser mais, que não é privilégio de alguns eleitos, mas direito dos homens". E apenas se estabelece no amor, uma vez que é um ato de compromisso, coragem e libertação, e não pretexto para manipulação e dominação (FREIRE, 2013, p. 112).

À vista disso, educar é assumir uma postura dialógica, entre sujeitos, para promover a conscientização na relação "eu" e o "outro", em comunhão, mediante uma prática social reflexiva e crítica que compreende que a ação conscientizadora é mútua e dialética e envolve diferentes saberes, histórias, culturas e identidades para transformação da 
realidade, das condições de vida e reversão dos problemas de degradação e exploração das demais espécies e da natureza em sua totalidade, rompendo com as adversidades que colocam em risco a liberdade humana (LOUREIRO, 2005). É por meio do diálogo que será possível mobilizar, organizar e elaborar mecanismos de enfrentamento aos estranhamentos emergidos durante a conjuntura atual, compreendendo que a luta não deverá ser construída com a finalidade de propor ações que venham substituir as obrigações do Estado para com o povo, mas na intenção de articularem reinvindicações para que as leis e regulamentações sejam seguidas diante do descaso com as questões socioambientais emergentes.

Outro ponto da pedagogia crítica de Freire que fornece contribuições para a EAC diz respeito aos temas geradores, dado que estes possuem potencial reflexivo e problematizador e podem ser uma alternativa para a análise dos problemas socioambientais contidos nas contradições, na estrutura e organização social, como também para instituir ações político-pedagógicas, mobilizar compreensões e desenvolver ações (DELIZOICOV; DELIZOICOV, 2014).

Além disto, o trabalho com os temas geradores, no pensamento educacional freireano, torna-se um elemento primordial para a efetivação de uma educação libertadora, posto que é mediante a apreensão desses temas que os seres humanos adquirem consciência em relação a sua situação no mundo e as contradições provenientes entre as relações homens-mundo (TORRES; FERRARI; MAESTRELLI, 2014). Conforme Martins e Bizerril (2015, p. 3), “o tema gerador é uma alternativa metodológica para a EA porque emerge da realidade social e histórica dos indivíduos envolvidos trazendo maior significado dos conteúdos para os educandos, que atuam como sujeitos participativos do processo".

De acordo com Delizoicov, Angotti e Pernambuco (2009), os temas geradores possuem como princípios básicos o estabelecimento do diálogo e da participação, a ruptura com o conhecimento nivelado ao senso comum, a inserção de uma compreensão da totalidade em relação à realidade e a exigência pela postura crítica por parte do educador, no sentido deste estar na ação e mesmo assim ter a capacidade de observar e problematizar o seu papel nesta. No entanto, é importante esclarecer que os [...] "temas geradores só são geradores de ação-reflexão-ação se forem carregados de conteúdos sociais e políticos com significado concreto para a vida dos educandos" (TOZONI-REIS, 2006, p. 103).

No cerne da EAC, o desenvolvimento de um trabalho pautado nos temas geradores como elementos representativos das relações entre sociedade, cultura e natureza [...] "pode permitir a práxis pedagógica que é reflexão e ação dos educandos e educadores sobre a 
realidade sócio-histórico-cultural vivida e a ser transformada" (TORRES; FERRARI; MAESTRELLI, 2014, p. 16).

A apreensão dos temas geradores e a tomada de consciência em relação às situações presentes, existenciais e concretas, em que vivem os seres humanos, é iniciada no exercício do diálogo e da conscientização. Desse modo, a intenção não é determinar ou impor uma visão de mundo, mas oportunizar o diálogo entre as diferentes concepções e olhares dos envolvidos em relação às contradições e situações existentes. Com isso, os sujeitos não podem ser tratados como se fossem seres programados e acabados e torna-se relevante investigar $[\ldots]$ "o seu pensamento-linguagem referido à realidade, os níveis de sua percepção desta realidade, a sua visão de mundo, em que se encontram envolvidos seus "temas geradores"” (FREIRE, 2013, p. 122).

Diante das considerações realizadas acerca do legado de Paulo Freire e como os seus pressupostos teóricos e práticos fornecem diversas implicações para a EAC, compreende-se que uma educação que se pretenda libertadora, problematizadora, crítica, emancipatória e transformadora têm como referência um processo pedagógico que conceba a dialogicidade como elemento central, no qual o educador-educando com o educandoeducador possam compartilhar saberes, anseios e desejos para desvelar as situações-limites e contradições sociais que envolvem a sua localidade, e promover ações e esforços que possibilitem a transformação da realidade, a formação integral e emancipação dos sujeitos, tecendo um comprometimento com o âmbito social e político, possibilitando, assim, a construção de sociedades mais sustentáveis, justas e democráticas (FREIRE, 1996; TOZONI-REIS, 2006; FREIRE, 2013; DICKMANN; STANQUEVISKI, 2019).

\section{Considerações finais}

Paulo Freire inspira reflexões que apontam encaminhamentos para a efetivação de uma EAC que valoriza a voz do outro, a colaboração, os laços comunitários, a construção de um pensamento e uma consciência crítica em relação ao mundo em que se vive, ampliando a sua leitura e compreendendo que existe um indissociabilidade entre os seres humanos e a natureza. Na perspectiva da EAC, as ações pedagógicas não são motivadas apenas pelo reconhecimento dos problemas existentes, mas na busca pela transformação mediante o estabelecimento de posturas mais sustentáveis e comprometidas com a totalidade. 
A proposição de uma EAC para (re)pensar a conjuntura atual e tecer possibilidades de enfrentamento e resistência ao retrocesso no contexto brasileiro, não exclui outras perspectivas de projetos de EA, mas reforça a EA enquanto instrumento político e ideológico, que muito além de promover questionamentos, diálogos e reflexões, possibilita subsídios para a ação e a luta coletiva em prol da construção de uma sociedade mais justa, fraterna e igualitária, em um contexto em que os direitos das minorias vem sendo ameaçados e retirados. Nesse sentido, cabe ressaltar que essa não deve ser uma luta para que o Estado se exima de suas funções, mas para a garantia da cultura democrática nas políticas públicas em EA, sejam elas novas ou estabelecidas em governos anteriores.

Articular o pensamento freireano à EAC, além de evidenciar uma demarcação teórico-prática, também contribui para o fortalecimento mútuo das frentes educativas que vêm sofrendo ataques constantes de representantes do governo federal. Assim, acredita-se que as ofensas a Freire, bem como à educação ambiental e às universidades, não cessarão, uma vez que os pressupostos estruturantes do seu pensamento, que buscam a superação de todas as formas de opressão e das contradições sociais, assim como o desvelamento da realidade e a defesa da liberdade e da democracia, ameaçam o projeto antidemocrático em curso.

\section{Referências}

BEHREND, Danielle Monteiro; COUSIN, Cláudia da Silva; GALIAZZI, Mariado Carmo. Base Nacional Comum Curricular: o que se mostra de referência à educação ambiental? Ambiente \& Educação - Revista de Educação Ambiental, v. 23, n. 2, p. 74-89, 2018. https://periodicos.furg.br/ambeduc/article/view/8425

BOURSCHEIT, Adem. Desrespeitar a política de segurança é uma marca dos 100 dias de governo Bolsonaro. Disponível em: https://www.oeco.org.br/reportagens/desmonte-depoliticas-ambientais-e-a-marca-dos-100-dias-de-governo-bolsonaro/ Acesso em: 19 dez. 2019.

BRASIL. Decreto n ${ }^{\circ}$ 9.759, de 11 de abril de 2019. Disponível em: http://www.in.gov.br/materia/lasset_publisher/Kujrw0TZC2Mb/content/id/71137350/do1e-2019-04-11-decreto-n-9-759de-11-de-abril-de-2019-71137335. Acesso em: 19 dez. 2019.

CARVALHO, Isabel Cristina Moura. Educação ambiental: a formação do sujeito ecológico. São Paulo: Cortez. 2012.

DAVIDOVICH, Luiz; CENTODUCATTE, Reinaldo; PEREGRINO, Fernando; VILELA, Evaldo. PORTO, André Gomyde. Carta de manifestação pública enviada ao presidente 
da república: em defesa do Instituto Nacional de Pesquisas Espaciais (INPE). São Paulo: SBPC, 2019. http://sbpcacervodigital.org.br/handle/20.500.11832/2905

DELIZOICOV, Demétrio; DELIZOICOV, Nadir Carvalho. A dimensão freireana na educação ambiental. In: LOUREIRO, Carlos Frederico Bernardo; TORRES, Julia Rezende. Educação Ambiental: dialogando com Paulo Freire. São Paulo: Cortez, 2014.

DELIZOICOV, Demétrio; ANGOTTI, José André; PERNAMBUCO, Marta Maria Castanho Almeida. Ensino de ciências: fundamentos e métodos. São Paulo: Cortez, 2009.

DICKMANN, Ivo; CARNEIRO, Sônia Maria Marchiorato. Paulo Freire e Educação ambiental: contribuições a partir da obra Pedagogia da Autonomia. Revista de Educação Pública, v. 21, n. 45, p. 87-102, 2012. http://periodicoscientificos.ufmt.br/ojs/index.php/educacaopublica/article/view/334

DICKMANN, Ivo; CECCHETTI, Elcio. Pedagogia da coletividade: ensaio freiriano sobre educação e política na atualidade brasileira. Revista Eletrônica Mestrado Educação Ambiental, v. 36, n. 1, p. 96-108, jan./abr. 2019. https://periodicos.furg.br/remea/article/view/8955

DICKMANN, Ivo; STANQUEVISKI, Claudemir. Pedagogia da resistência: aportes críticos para uma Educação Ambiental Freiriana. Quaestio, Sorocaba, SP, v. 21, n. 1, p. 59-80, jan./abr. 2019. http://periodicos.uniso.br/ojs/index.php/quaestio/article/view/3509

ESCOBAR, Herton. Brazilian president attacks deforestation data. Science. Vol. 365, Issue 6452, p. 419, 2016. https://science.sciencemag.org/content/365/6452/419

FEARNSIDE, Philip Martin. Os números do desmatamento são reais apesar da negação do presidente Bolsonaro. Disponível em:

https://amazoniareal.com.br/os-numeros-do-desmatamento-sao-reais-apesar-da-negacao-do presidente-bolsonaro/ Acesso em: 25 set. 2019.

FREIRE, Paulo. Educação e Mudança. São Paulo: Paz e Terra, 2016.

FREIRE, Paulo. Pedagogia do oprimido. Rio de Janeiro: Paz e Terra, 2013.

FREIRE, Paulo. Pedagogia dos sonhos possíveis. 55. ed. São Paulo/Rio de Janeiro: Paz e Terra, 2017.

FREIRE, Paulo. Pedagogia da autonomia: saberes necessários à prática educativa. 25. ed. Paz e Terra, 1996.

FREIRE, Paulo. Pedagogia da esperança: um reencontro com a Pedagogia do Oprimido. Paz e Terra, 1992.

FREITAS, Ana Lúcia Souza. Conscientização. In: STRECK, Danilo R.; REDIN, Euclides; ZITTKOSKI, Jaime José. Dicionário Paulo Freire. Belo Horizonte: Autêntica, 2018.

FRIZZO, Taís Cristine Ernst; CARVALHO, Isabel Crista Moura. Políticas públicas atuais no Brasil: o silêncio da educação ambiental. Revista Eletrônica do Mestrado em

Rev. Eletrônica Mestr. Educ. Ambient. Rio Grande, v. 37, n. 1, p. 145-165, jan/abr. 2020. E-ISSN 1517-1256 
Educação Ambiental, Ed. Especial EDEA, n. 1, p. 115-127, 2018.

https://periodicos.furg.br/remea/article/view/8567

GOUVEIA, André Barbosa. Ofício ANPED 046/2019. Moção de repúdio ao desmonte das políticas públicas de educação ambiental. Rio de Janeiro/Niterói, 2019.

http://www.anped.org.br/sites/default/files/images/mocao_17_oficio_anded_046-

2019 repudio ao desmonte das politicas ambientais.pdf

GUIMARÃES, Mauro. Educação ambiental crítica. In: LAYRARGUES, Philippe Pomier (coord.). Identidades da educação ambiental brasileira. Brasília: Ministério do Meio Ambiente, 2004.

LAYRARGUES, Philippe Pomier. Antiecologismo no Brasil: reflexões ecopolíticas sobre o modelo de desenvolvimentismo-extrativista-predatório e a desregulação ambiental pública. In: OLIVEIRA, Marcia Maria Dosciatti de, et al. Cidadania Meio Ambiente e Sustentabilidade. Caxias do Sul: EDUCS, 2017.

LAYRARGUES, Philippe Pomier. Quando os ecologistas incomodam: a desregulação ambiental pública no Brasil sob o signo do Anti-ecologismo. Revista de Pesquisa em Políticas Públicas, 2018. https://periodicos.unb.br/index.php/rp3/article/view/16812

LAYRARGUES, Philippe Pomier; LIMA, Gustavo Ferreira da Costa. As macrotendências político-pedagógicas da educação ambiental brasileira. Ambiente \& Sociedade, 17(1), 23 40, 2014. http://www.scielo.br/pdf/asoc/v17n1/v17n1a03.pdf

LAYRARGUES, Philippe Pomier. Identidades da educação ambiental brasileira. Brasília: Ministério do Meio Ambiente, 2004.

LEHER, Roberto. Autoritarismo contra a Universidade: o desafio de popularizar a defesa da educação pública. São Paulo: Fundação Rosa Luxemburgo, Expressão Popular, 2019.

LIMA, Gustavo Ferreira da Costa. Educação ambiental crítica: do socioambientalismo às sociedades sustentáveis. Educação e Pesquisa, 35(1), 145-163, 2009.

http://www.scielo.br/pdf/ep/v35n1/a10v35n1.pdf

LOUREIRO, Carlos Frederico Bernardo. Educação ambiental crítica: contribuições e desafios. Conceitos e práticas em educação ambiental na escola, p. 65, 2007.

LOUREIRO, Carlos Frederico Bernardo. Questões ontológicas e metodológicas da educação ambiental crítica no capitalismo contemporâneo. Revista Eletrônica Mestrado Educação Ambiental. Rio Grande, v. 36, n. 1, p.79-95, jan./abr. 2019.

https://periodicos.furg.br/remea/article/view/8954

LOUREIRO, Carlos Frederico Bernardo. Teoria Crítica. In: FERRARO JÚNIOR, Luiz Antonio. (Org) Encontros e Caminhos. Formação de educadores (as) ambientais e coletivos educadores. Brasília: Ministério do Meio Ambiente, 2005.

LOUREIRO, Carlos Frederico Bernardo.Trajetória e fundamentos da Educação Ambiental. São Paulo: Cortez, 2006. 
LOUREIRO, Carlos Frederico Bernardo; LIMA, Maria Jacqueline Girão Soares. A hegemonia do discurso empresarial de sustentabilidade nos projetos de educação ambiental no contexto escolar: Nova estratégia do capital. Revista Contemporânea de Educação, 2012. https://revistas.ufrj.br/index.php/rce/article/view/1672

MAB. Movimento dos atingidos por barragens. A privatização mata: análise do MAB sobre o crime da Vale em Brumadinho/MG. Secretaria Nacional. São Paulo: MAB, 2019.

MACHADO, Carlos Roberto da Silva; MORAES, Bruno Emílio. Educação ambiental crítica: da institucionalização à crise. Quaestio, Sorocaba, SP, v. 21, n. 1, jan./abr. 2019. http://periodicos.uniso.br/ojs/index.php/quaestio/article/view/3508

MARETTI, Cláudio C. Óleo no litoral do Nordeste e do Brasil. Disponível em: https://www.oeco.org.br/colunas/claudio-maretti/oleo-no-litoral-do-nordeste-e-do-brasil/ Acesso em: 20 dez. 2019.

MARTINS, Nayara Paula; BIZERRIL, Marcelo Ximenes Aguiar. Articulações entre os temas geradores de Paulo Freire e a Educação Ambiental na escola. Encontro Nacional de Pesquisa em Educação em Ciências - ENPEC, 10., Águas de Lindoia. Anais [...]. Águas de Lindoia, 2015. http://www.abrapecnet.org.br/enpec/xenpec/anais2015/lista_area_10.htm

NOGUEIRA, Vera Maria Ribeiro; MEDEIROS, Mara Rosange Acosta de. 2019 - um balanço nada promissor para a área social. Sociedade em Debate (Pelotas), v. 25, n. 3, p. 04-11, set./dez. 2019. http://revistas.ucpel.tche.br/index.php/rsd/article/view/2695/1602

PEREIRA, Eder Johnson de Area Leão; FERREIRA, Paulo Jorge Silveira Ferreira; RIBEIRO, Luiz Carlos de Santana; CARVALHO, Terciane Sabadini; PEREIRA, Hernane Borges de Barros Pereira. Policy in Brazil (2016-2019) threaten conservation of the Amazon rainforest, Environmental Science \& Policy, Volume 100, 2019. https://www.sciencedirect.com/science/article/abs/pii/S1462901119303818

PERNAMBUCO, Marta Maria Castanho Almeida; SILVA, Antonio Fernando Gouvêa da Silva. Paulo Freire: a educação e a transformação do mundo. In: CARVALHO, Isabel Cristina Moura de; GRÜN, Mauro; TRAJBER, Rachel. Pensar o Ambiente: bases filosóficas para a Educação Ambiental. Brasília: Ministério da Educação, 2006.

SAUVÉ, Lucie. Uma cartografia das correntes em Educação Ambiental. In: SATO, Michèle Tomoko; CARVALHO, I. C. M. (Orgs.). Educação Ambiental - pesquisas e desafios. Porto Alegre: Artmed, 2005.

SBPC. Manifesto do conselho da SBPC em defesa do instituto nacional de pesquisas espaciais (INPE). 2019. http://portal.sbpcnet.org.br/noticias/conselho-da-sbpc-lancamanifesto-em-defesa-do-inpe/

SENNA, Mônica de Castro Maia. Que vozes querem calar? Ameaças às instituições participativas no início do governo Bolsonaro. Disponível em: https://cee.fiocruz.br/?q=ANALISE-DE-CONJUNTURA. Acesso em: 12 jan. 2019. 
SILVA, Antonio Fernando Gouvêa da Silva; PERNAMBUCO, Marta Maria Castanho Almeida. Paulo Freire: uma proposta pedagógica ético-crítica para a educação ambiental. In: LOUREIRO, Carlos Frederico Bernardo; TORRES, Juliana Rezende. Educação Ambiental: dialogando com Paulo Freire. São Paulo: Cortez, 2014.

SILVA, Luciana Ferreira. Educação Ambiental Crítica: entre ecoar e recriar. Tese de Doutorado (Educação). São Paulo: Universidade de São Paulo, 2009.

https://teses.usp.br/teses/disponiveis/48/48134/tde-28052009-171742/publico/TESE.pdf

SORRENTINO, Marcos; TRAJBER, Raquel; MENDONÇA, Patrícia; FERRARO JUNIOR, Luiz Antônio. Educação Ambiental como Política Pública. Educação e Pesquisa, São Paulo, v. 31, n. 2, p. 285-299, maio/ago. 2005.

http://www.scielo.br/pdf/ep/v31n2/a10v31n2.pdf

TORRES, Juliana Rezende. Educação ambiental crítico-transformadora no contexto escolar: um exemplar. DICKMANN, Ivo; BATTESTIN, Cláudia. Educação ambiental na América Latina. 1. ed. - Chapecó: Plataforma Acadêmica, 2018.

TORRES, Juliana Rezende; FERRARI, Nadir; MAESTRELLI, Sylvia Regina Pedrosa. Educação ambiental crítico-transformadora no contexto escolar: teoria e prática freireana. In: LOUREIRO, Carlos Frederico Bernardo; TORRES, Juliana Rezende. Educação Ambiental: dialogando com Paulo Freire. São Paulo: Cortez, 2014.

TOZONI-REIS, Marília Freitas Campos. Temas ambientais como temas geradores: contribuições para uma metodologia educativa ambiental crítica, transformadora e emancipatória. Educar em revista, v. 22, n. 27, 2006.

https://revistas.ufpr.br/educar/article/view/6467

TOZONI-REIS, Marília Freitas Campos. Sobre educar e transgredir. Editorial. Ciênc. Educ., Bauru, v. 25, n. 1, p. 3-4, 2019.

http://www.scielo.br/scielo.php?script=sci arttext\&pid=S1516-73132019000100003

TREIN, Eunice Schilling. A Educação Ambiental Crítica: crítica de que? Revista Contemporânea de Educação. v. 7, n. 14, p. 304-318, ago/dez. 2012. https://revistas.ufrj.br/index.php/rce/article/view/1673 